\title{
Crack closure and stress intensity factor measurements in nodular graphite cast iron using 3D correlation of laboratory X-ray microtomography images
}

Nathalie Limodin ${ }^{a}$, Julien Réthoré ${ }^{b}$, Jean-Yves Buffière ${ }^{a}$, Anthony Gravouil ${ }^{b}$, François Hild ${ }^{c}$, Stéphane Roux'.

(a) MATEriaux Ingénierie et Sciences (MATEIS), INSA-Lyon / CNRS-UMR 5510, Bât. Saint Exupéry, 20 avenue Albert Einstein, F-69621 Villeurbanne Cedex, France

(b) Laboratoire de Mécanique des Contacts et des Structures (LaMCoS), INSA-Lyon / CNRS-UMR 5259, 20 avenue Albert Einstein, F-69621 Villeurbanne Cedex, France

(c) Laboratoire de Mécanique et Technologie (LMT-Cachan), ENS Cachan / CNRS / UPMC / PRES UniverSud Paris, 61 avenue du Président Wilson, F-94235 Cachan Cedex, France

\begin{abstract}
D tomographic images of a nodular graphite cast iron obtained using a laboratory X-ray source were used to analyze the opening of a fatigue crack during in-situ mechanical loading. Direct image analysis and digital image correlation are utilized to obtain the 3D morphology and front location of the crack as well as the displacement fields in the bulk of the specimen. From DIC results, it is possible to extract the Crack Opening Displacement (COD) map in the whole sample cross-section and to compute Stress Intensity Factors (SIF) all along the crack front even for COD values that are less than the image resolution. The comparison of COD maps with local values of SIF enabled for an estimation of the opening SIF, $K_{o p}$, equal to $6 \mathrm{MPa} \sqrt{\mathrm{m}}$.
\end{abstract}

Keywords: X-ray microtomography, 3D Digital Image Correlation, Stress Intensity Factors, Nodular graphite cast iron.

\section{Introduction}

Fatigue crack closure was first described by Elber [1] more than 30 years ago. Although it is a critical issue for life time predictions through Paris' laws (with the use of effective stress 
intensity factor ranges, $\Delta K_{\text {eff }}$ ), there is still no unified method of measurement that reaches general consensus. Crack closure occurs when the crack surfaces come into contact before the minimum load of the fatigue cycle is reached. The underlying mechanisms are diverse and may operate simultaneously; the reader is referred to ref. [2] for a more complete description. For example, a growing crack leaves behind a plastically deformed zone that is adjacent to the crack faces. This plastic wake induces early closure of the crack during unloading via a mechanism called Plasticity-Induced Crack Closure (PICC). Furthermore, asperities on the crack faces may also result in premature contact and induce RoughnessInduced Crack Closure (RICC). This mechanism becomes significant near the fatigue threshold when crack paths are highly crystallographic or under mode II or III loading that favours asperity contacts; in this case, closure concentrates in regions where the crack changed its direction of propagation [3]. Therefore, ideally, to measure crack closure and identify the operative closure mechanism, one needs a way to measure precisely the crack mouth displacements or contact along the crack front knowing the topography of the crack.

Measurements at the surface of a sample during a loading/unloading cycle have been performed using for example scanning electron microscopy [4]. Surface measurements allow one to visualize crack shapes and to analyze closure changes with the crack length [5]. However the relevance of this kind of measurement with respect to the bulk of the sample can be questioned. Bulk measurements of crack closure involve indirect observations from crack growth, e.g. with potential drop or acoustic emission, and with mechanical compliance curves [6]. This last method is the most widely used. The loss of linearity of the displacement-load curve recorded during unloading of the specimen delimits the closure load. However, the result may depend on the positioning of the displacement gauge, namely, at the crack mouth, at the back face of the specimen, behind the crack tip within the specimen (push-rod gauge) or near the crack tip at the surface [6]. With these techniques, no information on the relationship between crack topography and closure can be obtained as the detailed crack shape is not available. 
Three-dimensional visualisation of cracks in optically opaque materials such as metals is now possible using high resolution X-ray tomography [7-13]. So far, synchrotron X-rays have been used for this kind of studies as crack detection is enhanced by the high spatial coherence of X-ray beams available at modern (third generation) synchrotron facilities [14]. However, the use of synchrotron radiation puts a strong limit on the number of experiments that can be carried out in situ.

3D tomography images can be used, in principle, to evaluate the 3D displacement field at the crack tip in a specimen under load. In practice, this can be achieved using two different methods, namely Particle Tracking (PT) and Digital Image Correlation (DIC). Particle Tracking consists in measuring the displacements of microstructural features or markers inside the material. These markers are first identified by their gravity centre. Then, they are individually tracked between 3D images of the same specimen under different loads in order to compute the global displacement field inside the specimen. The DIC method is well established for computing displacements and strains on the surface of samples or structures [15-17]. It consists in measuring displacement fields between image pairs of the same specimen at different loads. The displacement field is obtained, using the so-called brightness conservation, so that the image of the loaded sample is matched to the reference image when pixel locations are corrected for by the measured displacement field. Recent developments have made possible the extension of this Galerkin technique to 3D displacement measurements in the bulk of specimens using 3D tomography images [18]. The uncertainty level of the latter is usually smaller than that of the former.

Both techniques have been applied to very different materials (Table 1). For example, the architecture in a trabecular bone [19] or in an open-cell aluminium foam [20] has been proved a valid texture for 3D DIC while microporosity in an aluminium alloy has been successfully used for particle tracking $[21 ; 22]$. The resolution of both techniques depends directly on the presence of numerous and finely dispersed microstructural features inside the material and those features should not break nor deform heavily upon loading. If the material 
does not possess a natural texture that meets these requirements, artificial markers may be added. For example, tungsten particles were added to an aluminium matrix [23; 24] and microholes were laser-drilled in a dispersion-strengthened copper alloy [25] to allow for strain mapping in tensile testing for strain values ranging from $3[23 ; 25]$ to $22 \%$ [25]. However, the influence of artificial markers on the matrix behaviour is difficult to assess. Increasing the number of artificial markers enhances the spatial resolution of strain mapping via tracking methods but it may also reinforce their potential perturbation effect. Whenever possible, the use of a material that possesses a natural texture suitable for DIC/PT is thus preferable.

Measurement of crack closure has been carried out by manual tracking of microstructural features using high resolution synchrotron radiation $(0.7 \mu \mathrm{m}$ voxel size). It drew interesting results on the relationship between the crack shape and local values of the stress intensity factor [21]. However, this technique has the disadvantage that crack tip displacements are not measured automatically.

This paper is a first attempt to evaluate crack closure in a widely used structural material, i.e. a nodular graphite cast iron where the graphite nodules act as natural markers to determine 3D displacements and stress intensity factors by correlating images obtained with standard laboratory X-ray tomography equipment.

\section{Material and experimental methods}

\subsection{Material}

The material of this study is a ferritic cast iron whose composition is $3.4 \mathrm{wt} \% \mathrm{C}, 2.6 \mathrm{wt} \% \mathrm{Si}$, $0.05 \mathrm{wt} \% \mathrm{Mg}, 0.19 \mathrm{wt} \% \mathrm{Mn}, 0.005 \mathrm{wt} \% \mathrm{~S}$, and $0.01 \mathrm{wt} \% \mathrm{P}$. After casting and heat treatment (ferritization at $880{ }^{\circ} \mathrm{C}$ followed by air cooling) the microstructure obtained is a ferritic matrix (98 wt $\%$ ferrite and $2 \mathrm{wt} \%$ perlite; average grain size $50 \mu \mathrm{m}$ ) with a $14 \%$ volume fraction of graphite nodules. Carbon (nodules) and iron (matrix) have atomic numbers that are different enough to give a strong X-ray attenuation contrast. Therefore, the spherical nodules, which 
are homogeneously distributed inside the matrix, are easily imaged by tomography and they can be used as natural markers for image correlation in the 3D reconstructed images. The average nodule diameter of $45 \mu \mathrm{m}$ is large enough to allow for a relatively low resolution voxel size to be used for tomography. This also enables one to observe millimetric samples, the only limitation for the sample size being the overall attenuation of the material that has to allow for, at least, a $10 \%$ transmission of the incoming X-ray beam. The fatigue crack interactions with the microstructure gives a roughness of the crack path of the order of the grain / nodule size. The material Young's modulus, yield stress and Poisson's ratio are equal to $175 \mathrm{GPa}, 315 \mathrm{MPa}$, and 0.27 , respectively. More details on the microstructure and mechanical properties of the material can be found in ref. [26].

\subsection{Fatigue pre-cracking}

A notched fatigue specimen with cross-section $6 \times 4 \mathrm{~mm}$ (see Figure 1a) was pre-cracked at room temperature using a maximum load of $3,217 \mathrm{~N}$ (stress ratio: 0.1 , frequency $10 \mathrm{~Hz}$ ). The specimen faces were mirror polished prior to the pre-cracking experiment and an optical travelling microscope was used to detect crack initiation and monitor crack propagation in situ. Fatigue testing was periodically interrupted and the specimen held at mean load to ease crack length measurement. When a crack longer than $350 \mu \mathrm{m}$ was observed, a load-

shedding technique was applied to maintain a maximum stress intensity factor, $K_{\max }$, less than $12.8 \mathrm{MPa} \sqrt{\mathrm{m}}$ in order to make sure that a small-scale yielding condition prevailed at the crack tip (estimated plastic zone size in plane strain: $170 \mu \mathrm{m}$ ). Fatigue cycling was stopped as soon as a $1.5 \mathrm{~mm}$ long crack was observed. For the tomography experiment, a smaller specimen with a square cross-section of $1.6 \times 1.55 \mathrm{~mm}^{2}$ (Figure $1 \mathrm{~b}$ ) was cut by electro discharge machining in the larger sample (Figure 1a) so that it contains only a part of the total fatigue crack tip with a crack size greater than the grain / nodule size. One face of the small specimen used for the present study contains the crack tip that was at the surface of the larger sample while the other face contains the crack tip that was at the centre of the larger sample. 


\subsection{X-Ray Microtomography}

The X-ray microtomography experiments were performed using a computed tomography system V-Tomex (Phoenix X-ray) fitted with a Nanofocus tube whose acceleration voltage can be adjusted from 10 to $160 \mathrm{kV}$. In the present work, a $95 \mathrm{kV}$ acceleration voltage was selected to ensure a $10 \%$ transmission of the X-ray beam through the $1.6 \times 1.55 \mathrm{~mm}^{2}$ crosssection of the sample. The specimen was placed on a rotating stage in the tomography chamber between the X-ray source and an amorphous Si diode array detector of dimensions $1920 \times 1536$ voxels. A set of 900 radiographs (scan) were taken while the sample was rotating over $360^{\circ}$ along its vertical axis. With an acquisition time per image of $500 \mathrm{~ms}$, one scan lasted about $45 \mathrm{~min}$. A miniature loading device ${ }^{1}$ was used to load the specimen (see Figure 1c). The distance between the sample and the tube could thus be reduced to $15.9 \mathrm{~mm}$ resulting in an image voxel size of $3.5 \mu \mathrm{m}$ (divergent beam). The specimen was loaded from $13 \mathrm{~N}$ up to $217 \mathrm{~N}$ in six incremental steps. A scan was started as soon as stability of the load was reached, i.e. at $13,44,82,130,185$ and $217 \mathrm{~N}$. Reconstruction of the tomographic data was performed with a filtered back-projection algorithm using datos $\mid x-$ acquisition software developed by Phoenix. It provides a 3D image with a 16 bit greyscale colormap that is proportional to the X-ray attenuation coefficient. Definition of a Region Of Interest $(\mathrm{ROI})$ that is focused on the crack reduced the image size to $500 \times 700 \times 480$ voxels; a $2 \mathrm{D}$ section of this image is shown in Figure $1 \mathrm{~b}$. For the sake of clarity, all the images are presented using the same coordinate system represented in Figure 1 with loading axis along $x$, crack propagation in the $y$ direction and sample thickness along $z$.

\subsection{Digital image correlation}

A C8-DIC multiscale algorithm with eight node cubic element was used to compute the displacement fields in the loaded specimen. Details about the method can be found in ref. [18]. The image acquired at minimum load, i.e. $13 \mathrm{~N}$, is used as the reference image of the computation (Figure 2). A ROI of $592 \times 416 \times 400$ voxels was centred on the original 
image of $700 \times 500 \times 480$ voxels. 8 -node cubic elements were used. A resolution analysis was performed to choose the relevant size of the element for correlation. Different displacement values in the $[0,1]$-voxel range are numerically prescribed to the reference picture. Then, the correlation algorithm is applied to this pair of images, thus allowing for an evaluation of the average error and uncertainty, which is equal to the standard deviation of the displacement about its mean value, for different sizes of elements (Figure 3). An increase in the element size results in a reduction of the mean error and standard uncertainty. However, even though the displacement uncertainty is the lowest for large elements, the heterogeneity of the displacement prompts one to use small sizes. Therefore an element size of 16 voxels was chosen as good compromise resulting in a mean displacement error of $3.3 \times 10^{-3}$ voxel and a standard uncertainty of $8.7 \times 10^{-2}$ voxel.

The image of the loaded specimen corrected by the displacements measured with DIC gives the "corrected image" shown in Figure 2. The presence of a discontinuity, i.e. the crack itself, impedes perfect matching of the image of the deformed sample to the reference image when the deformed image is corrected by the estimated displacement field. The difference between the reference and the deformed-and-corrected images is the residual error map that provides valuable information about the crack geometry.

\subsection{Stress Intensity Factors extraction}

From the measured displacement field, it is proposed to extract SIFs. First, least squares techniques are implemented by using $2 \mathrm{D}$ solutions [27-30]. An alternative technique to determine SIFs is to evaluate directly the $J$-integral along a given contour [31]. However, only few measurement data are used and strains and stresses are to be computed. To avoid this drawback, interaction integrals [32] are used for extracting SIFs from a discrete displacement field [33; 34]. This last technique can be extended to the analysis of 3D cracks [35]. It will not be used in the following. Instead, the technique proposed by Hamam et al. [27] will be followed. 
It is assumed that each of the node layers orthogonal to the mean direction of the crack front $((x, y)$ plane in Figure 2) can be treated separately. For each of these planes (nearly orthogonal to the crack front), the 3D displacement field is projected in a least squares sense onto a basis that includes 2D solutions for a cracked solid (mode I and mode II) as well as mode III asymptotic solutions. Following Williams [36], a closed-form solution for the in-plane displacements $\underline{v}$ is derived from Kolossov-Muskhelishvili's potentials [37]

$$
\underline{v}(r, \theta)=\sum_{n}\left[\omega_{n} \underline{\Omega}_{n}(r, \theta)+v_{n} \underline{Y}_{n}(r, \theta)\right]
$$

where $\omega_{n}$ and $u_{n}$ are real numbers, $n$ the number of terms of Williams' series. The reference field for mode $\mathrm{I}$ is

$$
\underline{\Omega}_{n}=\frac{r^{n / 2}}{2 \mu \sqrt{2 \pi}}\left[\kappa \exp \left(i \frac{n}{2} \theta\right)-\frac{n}{2} \exp \left\{i\left(2-\frac{n}{2}\right) \theta\right\}+\left((-1)^{n}+\frac{n}{2}\right) \exp \left\{-i \frac{n}{2} \theta\right\}\right]
$$

and for mode II

$$
\underline{\mathrm{Y}}_{n}=\frac{i r^{n / 2}}{2 \mu \sqrt{2 \pi}}\left[\kappa \exp \left(i \frac{n}{2} \theta\right)+\frac{n}{2} \exp \left\{i\left(2-\frac{n}{2}\right) \theta\right\}-\left((-1)^{n+1}+\frac{n}{2}\right) \exp \left\{-i \frac{n}{2} \theta\right\}\right]
$$

where $r$ and $\theta$ denote the in-plane coordinates associated to the usual crack tip frame, $\mu$ Lamé's shear modulus, and $k$ a dimensionless elastic (or Kolossov) coefficient related to Poisson's ratio $v$ according to $(3-v) /(1+v)$ for plane stress conditions or $3-4 v$ for plane strain conditions (used in the sequel).

The factor $\sqrt{2 \pi}$ is introduced to match the usual definitions of $K_{/}$and $K_{/ /}$SIFs [38], which are thus equal respectively to the amplitudes $\omega_{1}$ and $U_{1}$ associated with the fields $\underline{\Omega}_{1}$ and $\underline{Y}_{1}$.

Let us note first that the status of the fields $\underline{\Omega}_{n}$ and $\underline{Y}_{n}$ is very different for $n$ less than or greater than 1. For $n>1$, the fields are called subsingular. They have no impact on the crack tip. Conversely, the attached stress fields increase with the distance to the crack tip. Such functions are thus useful to match the vicinity of the crack tip with the remote geometry, or 
boundary conditions. However, since their impact on the crack tip process zone is negligible, one does not insist here on the structure of these fields. For $n<0$, the fields are referred to as supersingular. Traditionally, the supersingular fields are ignored because their asymptotic behaviour near the crack tip is non-physical (i.e. diverging energy density). However, for the present purpose, since the crack tip process zone is cut out from the domain of analysis, one does not have to reject these solutions [27]. However, it makes no sense to extrapolate them inside the process zone. They rather characterize the (vanishing) influence of non-linearities present in the process-zone in the outer elastic domain.

Out of plane motions $w$ induced by mode III displacements whose canonical field $\Xi$ reads

$$
\Xi=\frac{2}{\mu \sqrt{2 \pi}} r^{1 / 2} \sin \left(\frac{\theta}{2}\right)
$$

allow one to determine $K_{\text {III. }}$

Using least squares techniques, the measured displacement in each plane orthogonal to the crack front is projected onto the considered basis function. In practice, in-plane solutions are considered for $n$ ranging between -3 and 5. As mentioned above, negative $n$ values correspond to supersingular solutions whose coefficients are related to a shift of the crack tip position in the plane with respect to the tip of the equivalent "elastic crack" for $n=-1$. By cancelling out its contribution, the equivalent crack tip position is estimated [27]. A length scale proportional to the process zone size [27] is obtained when $\omega_{-3}$ is related to $\omega_{1}=K_{1}$. As all odd $n<0$ functions lead to singular displacements at the crack tip, the displacement data at nodes whose distance to the crack tip (or respectively to the crack mouth) is less than 20 (resp. 16) voxels are not considered in the analysis.

A key feature of this study is to use a laboratory tomograph. Consequently, special care is to be paid to the post-processing of the displacement fields. For DIC applications, it is essential that the two images to be registered are directly comparable. Due to thermal expansion of the x-ray tube, the distance between the beam source and the specimen may vary by tiny 
amounts during the experiment. The divergent beam geometry used for laboratory tomographs is such that this small distance change may result in significant (and spurious) image dilation. To decrease the voxel size and give a good crack description, the smallest possible sample / tube distance is used and even a modest thermal expansion in the tube results in an "apparent strain" of the order of $10^{-3}$, i.e. comparable to elastic strain levels in most metals. This apparent strain should not be considered as a real one. Even though consequences of this artefact are limited in some cases (e.g. when large strain levels are observed [39]), it is not true in the present analysis. The strategy is to account for dilation by introducing the corresponding displacement field in the basis on which the DIC displacement is projected. The additional field varies linearly with the distance to the centre of the specimen and thus it is similar to a T-stress field. For conditioning purposes, the T-stress field is replaced by the dilation field and the least-squares analysis is performed with this modified basis. In other words, it is assumed that the actual T-stress is negligible as compared to the artifactual dilation to be extracted. The geometry of the mode I test used herein is consistent with this assumption.

\subsection{X-FEM computation}

An elastic eXtended-Finite Element Method using ELFE3-D software was performed to validate the results obtained with the SIF extractor described above. Details about X-FEM applications to tomographic images can be found in refs. [40; 41]. The computation was carried out using the true crack geometry described by level sets computed from the correlation residuals. The material model is elastic and defined by Young's modulus and Poisson's ratio reported in Section 2.1. From the previous analysis, an experimental displacement field is considered with rigid body and dilation corrections. The three components of this corrected displacement field are then used as a remote displacement on the top and the bottom face of the extended finite element model. From the resulting numerical displacement field, the same procedure as in Section 2.5 (except that the dilation correction is not searched for) is applied to extract SIFs. 


\section{Results}

\subsection{Identification of 3D crack shape}

The grey level tomographic image of the cracked area can be thresholded in order to obtain a $3 \mathrm{D}$ rendering of the crack. However, for the cast iron used herein, similarity of grey values between the crack and the nodules makes it impossible to visualize the crack alone using this method (see Figure 4a). As reported in ref. [42], the growing crack is seeking out the nodules, which explains that the crack path deviates from a flat surface and that many nodules are embedded between the crack faces as shown in Figure 4a. To overcome this difficulty, the previously described residual error map was digitized on an 8 bit colormap and was thresholded using a 3D region growing algorithm from Amira software [43] to separate the voxels that belong to the crack from those that can be ascribed to noise such as computation error or image artefacts. Figure $4 \mathrm{~b}$ shows the crack geometry as observed from the thresholded residual field under maximum load, i.e. at $217 \mathrm{~N}$. The crack plane and tip position can be matched with those obtained from thresholding the tomographic image (Figure 4a) but the nodules are now erased so that the 3D topography of the crack is easier to observe. It is flat at a macroscopic scale but tortuous at the nodules scale. As this small sample was machined from one half of the larger pre-cracked specimen, the right-hand side of Figure 4 corresponds to the centre of the larger specimen, which underwent conditions close to plane strain during fatigue pre-cracking, while the other side corresponds to the free surface, i.e. closer to plane stress conditions. It is noticeable in Figure 4 that, due to tunnelling effect, the crack is longer in the former plane strain zone. For the sake of simplicity, left and right-hand sides of the specimen in Figure 4 will be referred to as short crack side and long crack side hereafter. 


\subsection{Crack tip position}

The 3D rendering of the crack surface from the residual error map largely depends on the threshold value that is used for the region growing algorithm. A threshold value that is too small might result in noise embedded in the thresholded crack while a value that is too large might underestimate the crack front location especially at the crack tip where the thickness of the $3 \mathrm{D}$ object to threshold is the smallest. It is to be stressed that the residual field is markedly different along the crack path for a crack opening of order of half a voxel. Hence, the estimate of the crack front position is slightly underestimated as compared to its actual position where the crack opening displacement vanishes, and becomes undetectable by this procedure. For small crack opening (below $217 \mathrm{~N}$ ), the crack tip visibility is better in the tomographic image than in the residual error probably because of some residual crack opening. Consequently, the crack tip was measured directly via visual inspection of the tomographic image in grey levels to check the position that can be deduced from the residual error field at maximum load $(217 \mathrm{~N})$ and validate the thresholding method. The methodology uses Image $\mathrm{J}$ software [44]. At a given load, the crack is viewed along the $z$ direction and artificially coloured to enhance contrast between the crack and the cast iron matrix. A plug-in allows one to retrieve the $(x, y)$ coordinates of the voxel that is manually selected at the crack tip. Thus, the crack tip position is determined in the thickness of the specimen and the resulting points are reported in Figure 5a. A rather large scatter of data is obtained at small loads when small crack opening results in limited crack tip visibility. This scatter is reduced at maximum load. Experimental points were fitted to analyse the variation of the apparent crack tip position, as observed via image analysis, with loading (Figure 5b). There is no visible evolution of the crack front between 13 and $44 \mathrm{~N}$. Only at $82 \mathrm{~N}$ does the crack seem to go deeper inside the specimen. This level probably corresponds to a full opening of the crack front. The crack front positions measured at $82 \mathrm{~N}$ and above on both sides of the sample are consistent with the crack lengths of 636 and $1084 \mu \mathrm{m}$ measured with an optical microscope. 
It is also noticeable that the apparent crack "advance" is substantially higher on the short crack side than on the long crack side.

\subsection{Displacements fields in the bulk of the specimen}

Only a limited amount of information is made available by such "simple" image analysis while image correlation provides the full displacement fields in the bulk of the specimen. The discontinuity induced by the crack is clearly visible in the $U_{x}$ displacement field (Figure 6) corresponding to mode I offering the possibility to study the crack opening change with load at a local scale. A slight discontinuity is also detectable in the $U_{y}$ and $U_{z}$ displacement fields, i.e. in Mode II and III. Mode II displacement or in-plane shear is localized on the right-hand side of Figure 4 where the crack deviates from the overall mean crack plane; the difference in $U_{y}$ displacements between upper and lower crack faces remains less than 0.8 voxel (i.e. less than $3 \mu \mathrm{m}$ ) even under maximum load. Mode III displacement on both sides of the crack plane is distributed through the specimen thickness along the crack mouth with localization towards the short crack side at maximum load. $U_{z}$ displacement is less than 1.4 voxel (i.e. 5 $\mu \mathrm{m})$.

\subsection{Crack opening displacement}

The displacement field in mode I, $U_{x}$, is smooth and continuous away from the crack as shown in Figure 6 . Thus, the displacement jump $\left(\Delta U_{x}\right)$ on the crack surface is estimated from the computed difference between the $U_{x}$ values in two slices taken parallel to the average crack plane on both sides of the crack (Figure 6). The resulting COD map in the specimen cross-section is plotted for increasing load levels in Figure 7 with a colormap that is proportional to the value of crack opening. Values of $\Delta U_{x}$ greater than 3 times the standard uncertainty, i.e. 0.27 voxel or $1 \mu \mathrm{m}$, are assumed to correspond to a "real" crack opening so that black areas in Figure 7 correspond to crack faces still in contact. At $44 \mathrm{~N}$, contact areas are still observed at the crack front. Only at $82 \mathrm{~N}$ and above does the crack fully open on the short crack side and a non-negligible value of $\Delta U_{x}$ is observed at the position of the crack tip 
(depicted by a white line in Figure 7). Under maximum load, i.e. $217 \mathrm{~N}$, the opening at the crack mouth amounts to $19 \mu \mathrm{m}$, i.e. more than five voxels, and it decreases towards the crack tip making the tip positions more difficult to assess. It is visible that at 130 and $217 \mathrm{~N}$, the displacement jump goes farther than the crack tip position and that the opening values behind the crack tip are well above the opening level so that they could not be attributed to measurement noise only.

Profiles of $\Delta U_{x}$ from crack mouth to crack tip were extracted for each loading step on both sides of the specimen, i.e. along the dotted lines drawn in Figure 7, to obtain a more quantitative information. The resulting points are plotted in Figure 8 for the short and long crack side. Crack lengths reported in Figure 8 (indicated with arrows) were measured on the thresholded residual error map in Figure 4 so that they also correspond to the crack front position reported in Figure 7. They are shorter than the displacement jump extent by about 200 and $75 \mu \mathrm{m}$, respectively for the short and long crack side. At the smallest load (44 N), the crack is not completely open and $\Delta U_{x}$ shows variations from maximum values that are below the voxel size $(3.5 \mu \mathrm{m})$ to zero. The values of COD measured should be a square root function of the distance to the crack tip if a linear elastic behaviour prevail at the vicinity of the crack tip [45]. Thus, the solid line curves in Figure 8 correspond to the best fit curves that could be obtained for each profile. Above $130 \mathrm{~N}$, these fitted curves fail to represent experimental data close to the crack tip, probably because of the large plastic zone that develops at the crack tip at these load levels.

\subsection{Estimation of the Stress Intensity Factors}

The $K_{l}$ SIF could be computed directly from the curves shown in Figure 8 . However, this computation method does not give a full description of $K_{l}$ values along the crack front and it does not exploit the full 3D displacement field information. Last, the dilation artefacts have to be incorporated. Therefore, the above mentioned extraction method (cf. Section 2.5) was used to measure SIF values along the crack front for the different loading steps. The results obtained for $K_{l}, K_{/ l}$ and $K_{I I I}$ are reported in Figure 9. The short and long crack sides 
correspond to the left and right hand sides of Figure 9a to c respectively. In Figure 9a, the measured values of $K_{l}$ on both sides of the sample emphasize the importance of the 3D effect. On the side where the crack is shorter, $K_{l}$ is enhanced while it is reduced on the side where the crack is in advance due to the constraint exerted by the surrounding uncracked ligament. A 2D analysis would be unable to represent such an effect. The 3D X-FEM analysis predicts the same trend as the experimental values. Up to a $130 \mathrm{~N}$ load, an excellent match is obtained between the elastic X-FEM computation and the experimental points. Then, at $217 \mathrm{~N}$, the computed curve rises slightly higher as plasticity develops. In Figure $9 \mathrm{~b}$, values obtained for $K_{/ /}$show fluctuations around 0 through the sample thickness, i.e. from about 1 to $-1 \mathrm{MPa} \sqrt{\mathrm{m}}$ with $K_{/ /}$values that do not vary significantly with increasing load up to $130 \mathrm{~N}$ but do increase at $217 \mathrm{~N}$. $K_{\text {III }}$ has an almost zero value that tends to increase slightly with load as shown in Figure 9c. The X-FEM computation for $K_{I /}$ and $K_{I I I}$ (using measured boundary conditions obtained from DIC analyses) shows a good agreement with experimental points. Although the specimen was macroscopically loaded in mode I, small mixed mode displacements occurred.

The position of the crack tip calculated with the SIF extractor is plotted in Figure 10 within the sample thickness. At $82 \mathrm{~N}$ and above, the calculated crack tip position in Figure 10 is in agreement with the crack tip position observed in the grey level images although the calculated position is about 80 to $120 \mu \mathrm{m}$ deeper. In the SIF extractor, the crack length that is calculated corresponds to an equivalent elastic crack. Thus, the larger the plastic zone size at the crack tip, the longer the "equivalent elastic" crack as compared to the "real" or physical crack. Moreover, the manual procedure for estimating the crack front position (Figure 5) in the tomographic image is sensitive to the local crack opening displacement so that it tends to underestimate the crack front position. Both effects contribute to the observed differences.

\section{Discussion}


To the best of the authors' knowledge, this is the first time that crack opening displacement fields are measured at a local scale by applying DIC on 3D images obtained with a laboratory X-ray tomograph, an equipment which is becoming more and more widespread in materials science laboratories. A problem that is typical of this kind of equipment has arisen. The thermal expansion of the X-ray tube during tomographic data acquisitions results in artificial "dilation" of the sample. For the four studied load levels, spurious strains of the order of $10^{-3}$, $1.7 \times 10^{-3}, 1.6 \times 10^{-3}, 2.7 \times 10^{-3}$, respectively, were measured. This dilation superimposes on the real displacement field inside the sample under tensile loading and biases the interpretation of DIC results. In the present study, this artefact was solved by a correction added to the above-mentioned SIF extraction method. In the near future, other solutions will be tested to solve the problem directly at its source by cooling of the X-ray tube. Provided this dilation artefact is corrected for, the use of a laboratory X-ray source instead of a synchrotron facility facilitates the kind of experiment presented herein.

The DIC method can however only be applied to materials with finely dispersed and resolvable microstructural features. The nodular graphite cast iron used in this study is a widely used material whose microstructure (with natural markers) is perfectly suited for image correlation. However, the present study would not have been possible for example with the 2024 aluminium alloy used by Toda et al. [21; 22] where the natural markers used (pores) have a low volume fraction and a typical size about twice the voxel size used in the present study.

The displacement uncertainty reported in Figure 3 appears to be higher than the levels reported for 2D images [46]. A possible source of this larger uncertainty lies in the nature of the images used. Tomography images are prone to "noise" because of reconstruction artefacts and improvement in reconstruction of tomographic data may help one to decrease the DIC uncertainty. It is to be noted that, for a given element size, coarsening the image resolution, e.g. from 12 to $36 \mu \mathrm{m}$ per voxel, was reported to divide the DIC uncertainty by 
more than 3 [20]. However, in the present study, a small voxel size $(3.5 \mu \mathrm{m})$ was preferred in order to have an accurate mapping of the displacement field and of the crack morphology. An advantage of DIC is also that it allows for 3D rendering of the crack without resorting to threshold tomographic images. Compared to PT [21; 22], DIC is also a more automatic method. Although a robust and automatic particle tracking method is being developed to optimize the tracking efficiency [25], it has still not proved successful for cracked specimens. Besides, while application of PT to cracked specimens is restricted to the crack tip [21], DIC allows for an extended area to be studied, and the full 3D displacement field to be measured so that 3D maps of COD are accessible. Moreover, the exact position of the crack tip is not a pre-requisite to SIFs extraction. As explained in Section 2.5, SIFs are computed with respect to a calculated crack tip position (Figure 10) whose accurate position is not known a priori. In the present study, different techniques allowed for the detection of crack opening during progressive loading of the specimen. Using direct image analysis to retrieve the crack tip position, an advance of the apparent crack tip position is observed in Figure $5 \mathrm{~b}$ when the load increases from 44 to $82 \mathrm{~N}$; it is not visible in the residual error field probably because of the medium spatial resolution of the DIC field. This apparent crack advance may be related to PICC that developed during pre-cracking of the larger sample. The larger advance observed on the short crack side would then be consistent with the size of the plastic zone inherited from the larger specimen. At the former free surface of the large sample, the plane stress condition created a plastic zone size that is theoretically about 3 times greater than that in plane strain, i.e. at the long crack side. Consequently, this larger plastic zone exerts its influence on a longer distance away from the crack tip. It is noticeable that the plane stress plastic zone seems to influence a large part of the crack front away from the former free surface. In thin specimens, Chermahini et al. [47] also reported that the opening load decreases slightly from the free surface towards the centre of the specimen whereas in thicker specimen, the region of higher opening load was restricted to a relatively narrow region near the free surface as expected. However, in the present study, this result should be 
considered with caution as the cutting of the small tomography sample might induce stress relaxation so that the stress state that formerly existed inside the larger specimen might not be fully acting in the smaller specimen.

In the 3D images of the crack, a load of $82 \mathrm{~N}$ was sufficient to open the crack, and above this load level, the apparent crack tip position (Figure 5) did not vary significantly. However, non negligible values of COD are observed ahead of the crack tip location measured at maximum load (see Figure 8); they might be attributed to the presence of a plastic zone. At $217 \mathrm{~N}$, the mean stress on the uncracked ligament is about $60 \%$ of the monotonic yield strength. Generalized plasticity is thus not expected. However, due to dissymmetry of the crack and the vicinity of the free surface, the plastic zone size at the crack front is likely to increase rapidly, especially on the short crack side, and the confined plasticity condition may be violated at the crack front. This hypothesis is in agreement with the fact that an elastic computation (see 'E' in Figure 9a) was unable to perfectly match the experimental points at $217 \mathrm{~N}$, while a nearly perfect match was observed at $130 \mathrm{~N}$ and below.

Using the 3D displacement fields obtained from DIC, the SIF change along the crack front was obtained for the different load levels. $K_{/ /}$in Figure $9 \mathrm{~b}$ varies around a zero value and a small positive value is measured for $K_{/ I I}$ in Figure $9 \mathrm{c}$. Crack geometry and misalignment of the specimen inside the in-situ loading device and / or misalignment of the crack faces after fatigue pre-cracking of the large sample may explain some of this mixed mode displacement during tensile loading. However, mode II and III SIFs remain close to zero, and mode I is predominant, as expected from the prescribed "macroscopic" mechanical testing conditions. $K_{l}$ is observed to increase from the long crack side towards the short crack side in Figure 9a. This is the result of the 3D shape of the crack, namely, a locally lagging crack front induces a higher value of SIF $[48 ; 49]$.

By combining the results of Figure 7 and $9 a$ it is possible to give an estimate of the value of opening SIF, $K_{o p}$, assuming that mode $I$ is the main opening mode and, also, that the crack actually opens when the measured $\Delta U_{x}$ equals 0.27 voxel. Around $82 \mathrm{~N}$, the measured 
values of $K_{l}$ vary from 7.5 to $3.5 \mathrm{MPa} \sqrt{\mathrm{m}}$ from the short crack side (fully open) to the long crack side (crack locally closed). At $130 \mathrm{~N}, K_{l}$ varies from 13 to $6 \mathrm{MPa} \sqrt{\mathrm{m}}$ and both sides of the crack are fully open. The value of $K_{o p}$ can thus be estimated close to $6 \mathrm{MPa} \vee \mathrm{m}$. This level is in very good agreement with values reported in the literature by different authors on the same material but using mechanical compliance techniques [50-52]. This tends to indicate that DIC coupled with laboratory X-ray tomography can be trusted to assess crack closure in 3D studies of this type of material.

\section{Conclusions}

3D-DIC analyses on 3D microtomographic images obtained with a laboratory X-ray source were used to study fatigue crack closure in a nodular graphite cast iron. An in-situ testing machine enabled for progressive loading of the specimen in tension and 3D images acquired at different loading steps allowed for the detection of the opening load. The 3D images were further analyzed using 3D digital image correlation. The nodular graphite cast iron material is well adapted to the correlation technique with graphite nodules that act as natural markers. Compared to the tracking method used by Toda et al. [21; 22] to analyze crack closure in synchrotron X-ray microtomographic images, DIC is a more automatic method that provides the full displacement field inside the cracked sample. The measured displacement fields were then used to evaluate the COD maps in the specimen cross-section in order to visualize crack opening locally with an increased resolution compared to direct image analysis of the crack. A stress intensity factor extractor adapted for lab-CT, i.e. with correction for the artificial dilation induced by thermal expansion of the X-ray tube, permitted us to compute the stress intensity factor along the crack front from the 3D displacement fields. The confrontation of the COD maps with local SIF allowed for the estimation of a stress intensity factor for opening, $K_{o p}$, equal to $6 \mathrm{MPa} \sqrt{\mathrm{m}}$.

The method described herein could be potentially used to investigate the geometry of fatigue cracks in samples with a larger size (up to $5 \mathrm{~mm}$ with the present tomograph) relevant for 
engineering applications and corresponding to more complex loading cases (e.g. tension /

torsion loading). Besides, the tomography technique being non destructive, the same type of study can be performed in situ during fatigue crack propagation. Such experiments have been performed recently and are currently being analysed, they should allow to assess crack closure during mechanical cycling, and to correlate it to local crack growth.

\section{Acknowledgments}

This work was funded by the CETIM Foundation grant entitled PROPAVANFIS: 'Advanced methods for the experimental and numerical analyses of crack propagations under complex loadings.' The authors are also grateful to Dr. W. Ludwig for the use of his in-situ testing machine.

\section{References}

1 Elber W. The significance of fatigue crack closure. ASTM Special Technical Publication 486 1971;486:230 Scopus.

2 Suresh S.Fatigue of materials. Cambridge University Press; 1998.

3 Tanaka K, Akiniwa Y: Modeling of fatigue crack growth: mechanistic models. In Comprehensive structural integrity. Volume 4. 1. Edited by Milne I. Elsevier Ltd., Oxford, UK; 2003:165.

4 Zhang XP, Wang CH, Ye L, Mai YW. A study of the crack wake closure/opening behaviour of short fatigue cracks and its influence on crack growth. Materials Science and Engineering A 2005;406:195 Scopus.

5 Fleck NA, Smith RA. Crack closure - is it just a surface phenomenon?. International Journal of Fatigue 1982;4:157 Scopus.

$6 \mathrm{Xu}$ Y, Gregson PJ, Sinclair I. Systematic assessment and validation of compliance-based crack closure measurements in fatigue. Materials Science and Engineering A 2000;284:114 Scopus.

7 Ludwig W, Buffière JY, Savelli S, Cloetens P. Study of the interaction of a short fatigue crack with grain boundaries in a cast al alloy using X-ray microtomography. Acta Materialia 2003;51:585 Scopus.

8 McDonald SA, Preuss M, Maire E, Buffière JY, Mummery PM, Withers PJ. X-ray tomographic imaging of Ti/SiC composites. J Microsc 2003;209:102 $\underline{\text { Scopus. }}$.

9 Marrow TJ, Buffière JY, Withers PJ, Johnson G, Engelberg D. High resolution X-ray tomography of short fatigue crack nucleation in austempered ductile cast iron. International Journal of Fatigue 2004;26:717 Scopus. 
10 Ferrié E, Buffière J, Ludwig W: 3d characterisation of the nucleation of a short fatigue crack at a pore in a cast al alloy using high resolution synchrotron microtomography. In Fatigue Damage Of Structural Materials V, Sep 19-24 2004. Edited by Elsevier Ltd, Oxford, OX5 1GB, United Kingdom; 2005:1215-1220. [International Journal of Fatigue, vol 27] Scopus

11 Buffière JY, Ferrié E, Proudhon H, Ludwig W. Three-dimensional visualisation of fatigue cracks in metals using high resolution synchrotron x-ray micro-tomography. Materials Science and Technology 2006;22:1019 Scopus.

12 Verdu C, Adrien J, Buffière JY. Three-dimensional shape of the early stages of fatigue cracks nucleated in nodular cast iron. Materials Science and Engineering A 2008;483484:402 Scopus.

13 Toda H, Yamamoto S, Kobayashi M, Uesugi K, Zhang H. Direct measurement procedure for three-dimensional local crack driving force using synchrotron x-ray microtomography. Acta Materialia 2008;56:6027 Scopus.

14 Cloetens P, Pateyron-Salome M, Buffiere JY, Peix G, Baruchel J, Peyrin F, Schlenker M. Observation of microstructure and damage in materials by phase sensitive radiography and tomography. Journal of Applied Physics 1997;81:5878 Scopus.

15 Sutton MA, McNeill SR, Helm JD, Chao YJ: Advances in two-dimensional and threedimensional computer vision. In Photomechanics. Volume 77. Edited by Rastogi P. Springer Berlin / Heidelberg; 2000:323.

16 Roux S, Hild F. Stress intensity factor measurements from digital image correlation: postprocessing and integrated approaches. International Journal of Fracture 2006;140:141 $\underline{\text { Scopus. }}$

17 Mekky W, Nicholson PS. The fracture toughness of $\mathrm{Ni} / \mathrm{Al}_{2} \mathrm{O}_{3}$ laminates by digital image correlation II: bridging-stresses and R-curve models. Engineering Fracture Mechanics 2006;73:583.

18 Roux S, Hild F, Viot P, Bernard D. Three-dimensional image correlation from x-ray computed tomography of solid foam. Composites Part A: Applied Science and Manufacturing 2008;39:1253 Scopus.

19 Bay BK, Smith TS, Fyhrie DP, Saad M. Digital volume correlation: three-dimensional strain mapping using X-ray tomography. Experimental Mechanics 1999;39:217 Scopus.

20 Verhulp E, Rietbergen BV, Huiskes R. A three-dimensional digital image correlation technique for strain measurements in microstructures. Journal of Biomechanics 2004;37:1313 Scopus.

21 Toda H, Sinclair I, Buffière JY, Maire E, Khor KH, Gregson P, Kobayashi T. A 3D measurement procedure for internal local crack driving forces via synchrotron $\mathrm{X}$-ray microtomography. Acta Materialia 2004;52:1305 Scopus.

22 Toda H, Sinclair I, Buffière JY, Maire E, Connolley T, Joyce M, Khor KH, Gregson P. Assessment of the fatigue crack closure phenomenon in damage-tolerant aluminium alloy by in-situ high-resolution synchrotron x-ray microtomography. Philosophical Magazine 2003;83:2429 $\underline{\text { Scopus. }}$

23 Nielsen SF, Poulsen HF, Beckmann F, Thorning C, Wert JA. Measurements of plastic displacement gradient components in three dimensions using marker particles and synchrotron x-ray absorption microtomography. Acta Materialia 2003;51:2407 Scopus. 
24 Haldrup K, Nielsen SF, Wert JA. A general methodology for full-field plastic strain measurements using $\mathrm{x}$-ray absorption tomography and internal markers. Experimental Mechanics 2008;48:199 Scopus.

25 Kobayashi M, Toda H, Kawai Y, Ohgaki T, Uesugi K, Wilkinson DS, Kobayashi T, Aoki Y, Nakazawa M. High-density three-dimensional mapping of internal strain by tracking microstructural features. Acta Materialia 2008;56:2167 Scopus.

26 Adrien J: Optimisation des cycles thermiques appliqués aux fontes g.s. ferritiques vis à vis des propriétés de fatigue (in french). $P h D$ thesis. Institut National des Sciences Appliquées de Lyon, Génie des Matériaux: Villeurbanne, INSA; 2004; http://docinsa.insalyon.fr/these/pont.php?id=adrien.

27 Hamam R, Hild F, Roux S. Stress intensity factor gauging by digital image correlation: application in cyclic fatigue. Strain 2007;43:181 Scopus.

28 Yoneyama S, Ogawa T, Kobayashi Y. Evaluating mixed-mode stress intensity factors from full-field displacement fields obtained by optical methods. Engineering Fracture Mechanics 2007;74:1399 Scopus.

29 Abanto-Bueno J, Lambros J. Investigation of crack growth in functionally graded materials using digital image correlation. Engineering Fracture Mechanics 2002;69:1695 Scopus.

$30 \mathrm{McNeill} \mathrm{SR}$, Peters WH, Sutton MA. Estimation of stress intensity factor by digital image correlation. Engineering Fracture Mechanics 1987;28:101 Scopus.

31 Huntley JM, Field JE. Measurement of crack tip displacement field using laser speckle photography. Engineering Fracture Mechanics 1988;30:779 Scopus.

32 Parks DM. A stiffness derivative finite element technique for determination of crack tip stress intensity factors. International Journal of Fracture 1974;10:487 Scopus.

33 Rethoré J, Roux S, Hild F. Noise-robust stress intensity factor determination from kinematic field measurements. Engineering Fracture Mechanics 2008;75:3763 Scopus.

34 Rethoré J, Gravouil A, Morestin F, Combescure A. Estimation of mixed-mode stress intensity factors using digital image correlation and an interaction integral. International Journal of Fracture 2005;132:65 Scopus.

35 Gosz M, Dolbow J, Moran B. Domain integral formulation for stress intensity factor computation along curved three-dimensional interface cracks. International Journal of Solids and Structures 1998;35:1763 Scopus.

36 Williams ML. On the stress distribution at the base of a stationary crack. ASME J. Appl. Mech. 1957;24:109.

37 Muskhelishvili NI.Some basic problems of the mathematical theory of elasticity. Noordhoff, Ltd., Netherlands; 1953.

38 Irwin GR. Analysis of the stresses and strains near the end of a crack traversing a plate. ASME J. Appl. Mech. 1957;24:361.

39 Hild F, Maire E, Roux S, Witz JF. Three dimensional analysis of a compression test on stone wool (submitted). 2009.

40 Ferrié E, Buffière JY, Ludwig W, Gravouil A, Edwards L. Fatigue crack propagation: in situ visualization using $\mathrm{x}$-ray microtomography and $3 \mathrm{~d}$ simulation using the extended finite element method. Acta Materialia 2006;54:1111 Scopus. 
41 Rannou J, Limodin N, Réthoré J, Gravouil A, Ludwig W, Baïetto-Dubourg MC, Buffière JY, Combescure A, Hild F, Roux S. Three dimensional experimental and numerical multiscale analysis of a fatigue crack. [submitted to] Computer Methods in Applied Mechanics and Engineering 2008.

42 Stokes B, Gao N, Reed PAS. Effects of graphite nodules on crack growth behaviour of austempered ductile iron. Materials Science and Engineering A 2007;445-446:374 Scopus.

43 [http://www.amiravis.com/]

44 [http://rsb.info.nih.gov/ij/]

45 Anderson TL.Fracture mechanics: fundamentals and applications. CRC Press; 1995.

46 Besnard G, Hild F, Roux S. "Finite-element" displacement fields analysis from digital images: application to Portevin-Le Chatelier bands. Experimental Mechanics 2006;46:789.

47 Chermahini R, Shivakumar K, Newman Jr J, Blom A. Three-dimensional aspects of plasticity-induced fatigue crack closure. Engineering Fracture Mechanics 1989;34:393 Scopus.

48 Newman JCJ, Raju IS. Stress-intensity factor equations for cracks in three-dimensional finite bodies. ASTM Special Technical Publication 1983;791:238 $\underline{\text { Scopus. }}$.

49 Branco R, Rodrigues D, Antunes FV. Influence of through-thickness crack shape on plasticity induced crack closure. Fatigue and Fracture of Engineering Materials and Structures 2008;31:209 $\underline{\text { Scopus. }}$.

50 Clément P, Angeli JP, Pineau A. Short crack behaviour in nodular cast iron. Fatigue of Engineering Materials and Structures 1984;7:251 $\underline{\text { Scopus. }}$

51 Ogawa T, Kobayashi H. Near-threshold fatigue crack growth and crack closure in a nodular cast iron. Fatigue \& Fracture of Engineering Materials \& Structures 1987;10:273 Scopus.

52 Wasen J, Heier E. Fatigue crack growth thresholds - the influence of Young's modulus and fracture surface roughness. International Journal of Fatigue 1998;20:737 Scopus.

\section{Figure captions}

Figure 1: $\quad$ Fatigue pre-cracking of (a) the large specimen from which a (b) small sample is obtained for (c) microtomography of in-situ loaded specimen.

Figure 2 : Extraction of the crack surface from Digital Image Correlation measurements.

Figure 3 : Displacement uncertainty and error expressed in voxel as functions of the element size when uniform sub-voxel displacements are prescribed.

Figure $4: 3 D$ rendering of the crack surface at maximum load from (a) the thresholded tomographic image and from (b) the residual error field. 
Figure 5 : Position of the crack front for different load levels: (a) experimental points and (b) fitting curves.

Figure 6 : Displacement (expressed in voxels) fields in the specimen volume under maximum load (macroscopic load applied along $x$ direction). The hatched planes drawn in the $U_{x}$ field indicate the $(y, z)$ planes used for COD mapping in Figure 7.

Figure 7 : Maps of $\Delta U_{x}$ displacement (COD) in the specimen cross-section with increasing load. The crack front is drawn in white and the dashed-lines along $y$ direction indicate the location of the profiles plotted in Figure 8.

Figure 8 : Change with load of the crack opening displacement profile along crack depth (a) on the short and (b) long crack side; the dashed-line corresponds to 3 times the uncertainty in $U_{x}$ and the arrow indicates the position of the crack front plotted in Figure 7 . The solid lines correspond to the best fitting curves.

Figure 9 : SIF values along the crack front for (a) Mode I, (b) Mode II and (c) Mode III; Measured ('FF') values of SIF (symbols) are compared to computed ('E') values (lines); the hatched area in (a) corresponds to the $K_{o p}$ range obtained from literature data.

Figure 10 : Crack tip position of the equivalent "elastic crack" based on the SIF extractor method (symbols); the solid lines correspond to the crack tip positions reported in Figure $5 \mathrm{~b}$ (visual inspection of tomographic images and smoothed by curve fitting).

${ }^{1}$ Courtesy of W. Ludwig - MATEIS/ESRF 
Table 1

\begin{tabular}{|c|c|c|c|c|c|c|c|c|}
\hline Reference & $\begin{array}{l}\text { X-Ray } \\
\text { source }\end{array}$ & Crack & $\begin{array}{l}\text { Voxel } \\
\text { size in } \\
\mu \mathrm{m}\end{array}$ & Method & Material & $\begin{array}{c}\text { Displacement } \\
\text { uncertainty } \\
\text { (in voxels) }\end{array}$ & $\begin{array}{c}\text { Section of } \\
\text { analysis ( } \mathrm{mm}) \\
\text { [subvolume in } \\
\text { voxels] }\end{array}$ & $\begin{array}{c}\text { Deformation range } \\
(\%)\end{array}$ \\
\hline [19] & laboratory & no & 35 & DIC & Trabecular bone & $3.5 \times 10^{-2}$ & $\varnothing 15$ & $0.4-1.8$ \\
\hline [22] & \multirow{2}{*}{ synchrotron } & \multirow{2}{*}{ yes } & \multirow{2}{*}{0.7} & $\begin{array}{l}\text { Manual } \\
\text { tracking }\end{array}$ & \multirow{2}{*}{$\begin{array}{c}\text { Al2024-T351 with } \\
800 \text { pores } 7.2 \mu \mathrm{m} \\
\text { in } \varnothing\end{array}$} & $5 \times 10^{-1}$ & \multirow{2}{*}{$0.8 \times 0.9$} & \multirow{2}{*}{ Elastic } \\
\hline [21] & & & & Tracking & & $10^{-1}$ (on COD) & & \\
\hline [23] & synchrotron & no & 1.5 & Tracking & $\begin{array}{c}\text { Aluminium with } \\
\text { added }(5000) \mathrm{W} \\
\text { markers } 10 \mu \mathrm{m} \text { in } \\
\varnothing\end{array}$ & $2 \times 10^{-1}$ & $0.45 \times 0.45$ & $2.7-9.5$ (plastic) \\
\hline [20] & laboratory & no & $\begin{array}{c}36 \\
(20,12)\end{array}$ & DIC & $\begin{array}{l}\text { Open-cell } \\
\text { aluminium foam }\end{array}$ & $5 \times 10^{-2}$ & $\begin{array}{c}5 \times 5 \\
{[28 \times 16 \times 26]}\end{array}$ & No loading \\
\hline [24] & synchrotron & no & 1.5 & Tracking & $\begin{array}{c}\mathrm{Al} / \mathrm{AlO}_{2} \text { with added } \\
(\sim 38000) \mathrm{W} \\
\text { markers }\end{array}$ & $\begin{array}{c}5 \times 10^{-1} \text { (on } \\
\text { markers' } \\
\text { position) }\end{array}$ & $\varnothing 1\left[67^{3}\right]$ & 10 (plastic) \\
\hline [25] & synchrotron & no & 0.474 & $\begin{array}{c}\text { More } \\
\text { automatic } \\
\text { tracking }\end{array}$ & $\begin{array}{c}\text { Copper alloy with } \\
188 \text { artificial pores } \\
15 \mu \mathrm{m} \text { in } \varnothing\end{array}$ & $\begin{array}{l}1 \text { (on markers' } \\
\text { position) }\end{array}$ & $0.25 \times 0.3$ & $3.5-22$ (plastic) \\
\hline [18] & synchrotron & no & 4.91 & DIC & $\begin{array}{l}\text { Polypropylene } \\
\text { solid foam }\end{array}$ & $\begin{array}{c}3 \times 10^{-1}- \\
3 \times 10^{-2}\end{array}$ & $\varnothing 15\left[400^{3}\right]$ & $10-30$ \\
\hline
\end{tabular}




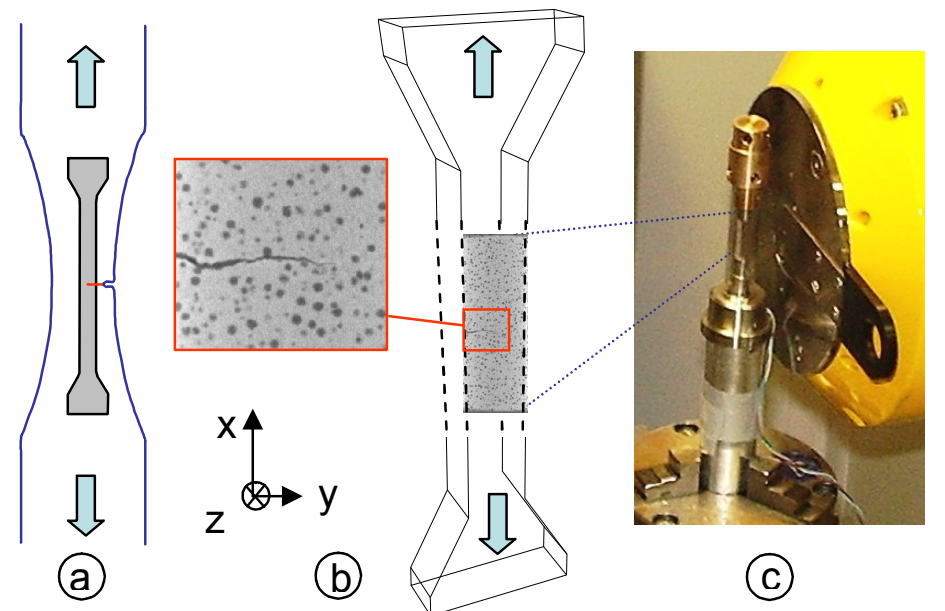

Figure 1: Fatigue pre-cracking of (a) the large specimen from which a (b) small sample is obtained for (c) microtomography of in-situ loaded specimen. 

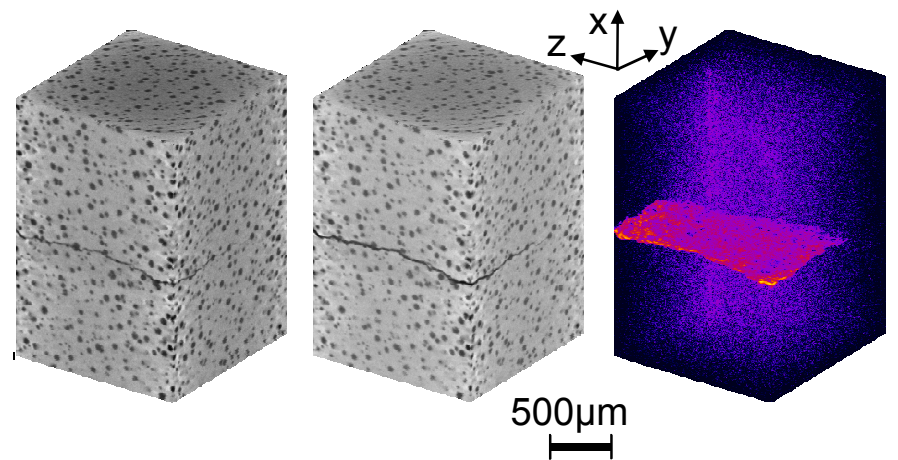

Reference Corrected image Residual error

Figure 2 : Extraction of the crack surface from Digital Image Correlation measurements. 


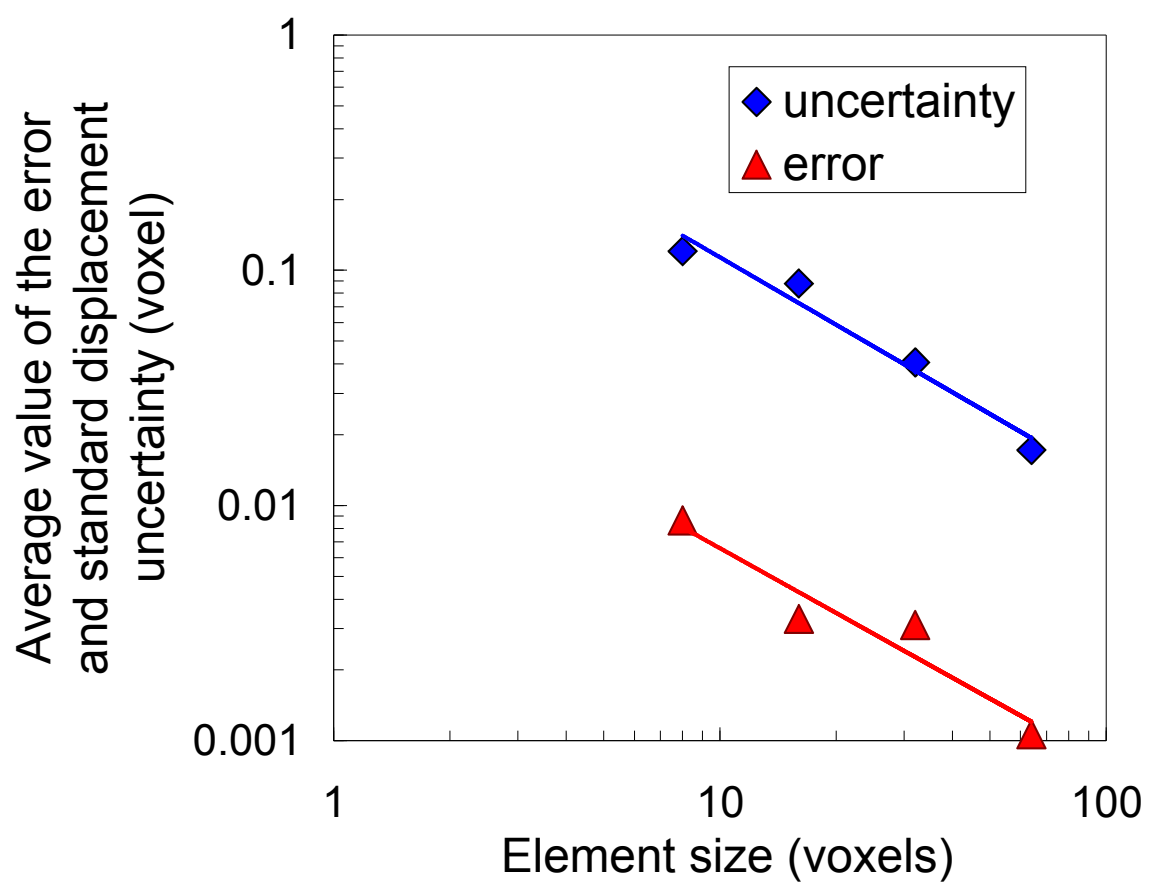

Figure 3 : Displacement uncertainty and error expressed in voxel as functions of the element size when uniform sub-voxel displacements are prescribed. 

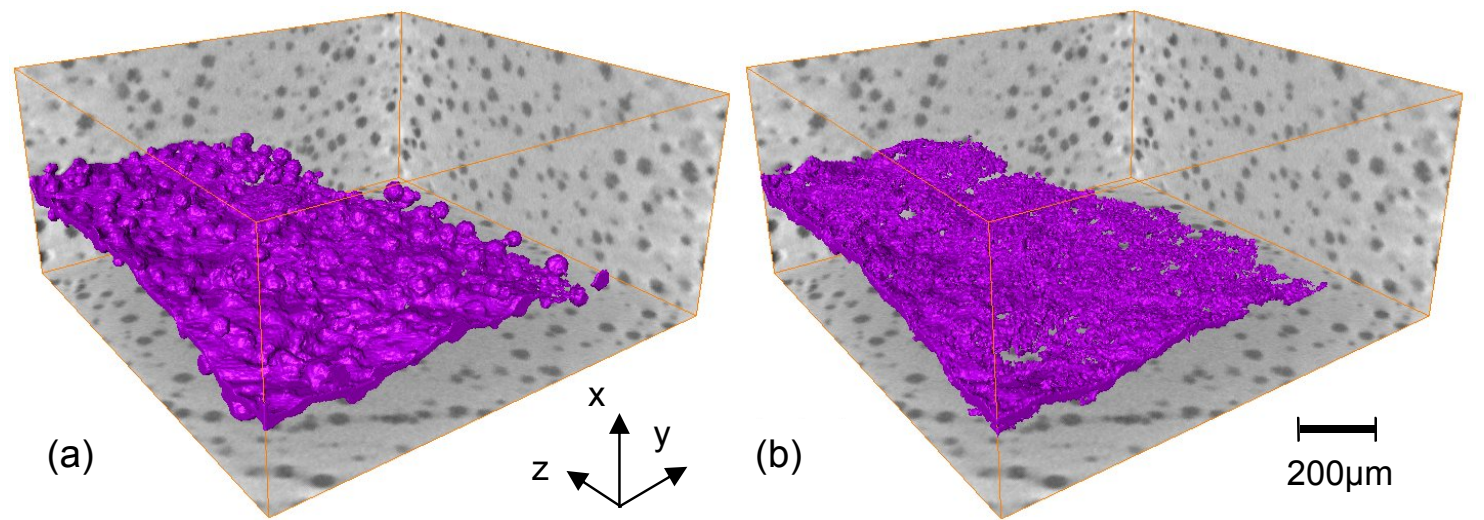

Figure 4 : 3D rendering of the crack surface at maximum load from (a) the thresholded tomographic image and from (b) the residual error field. 

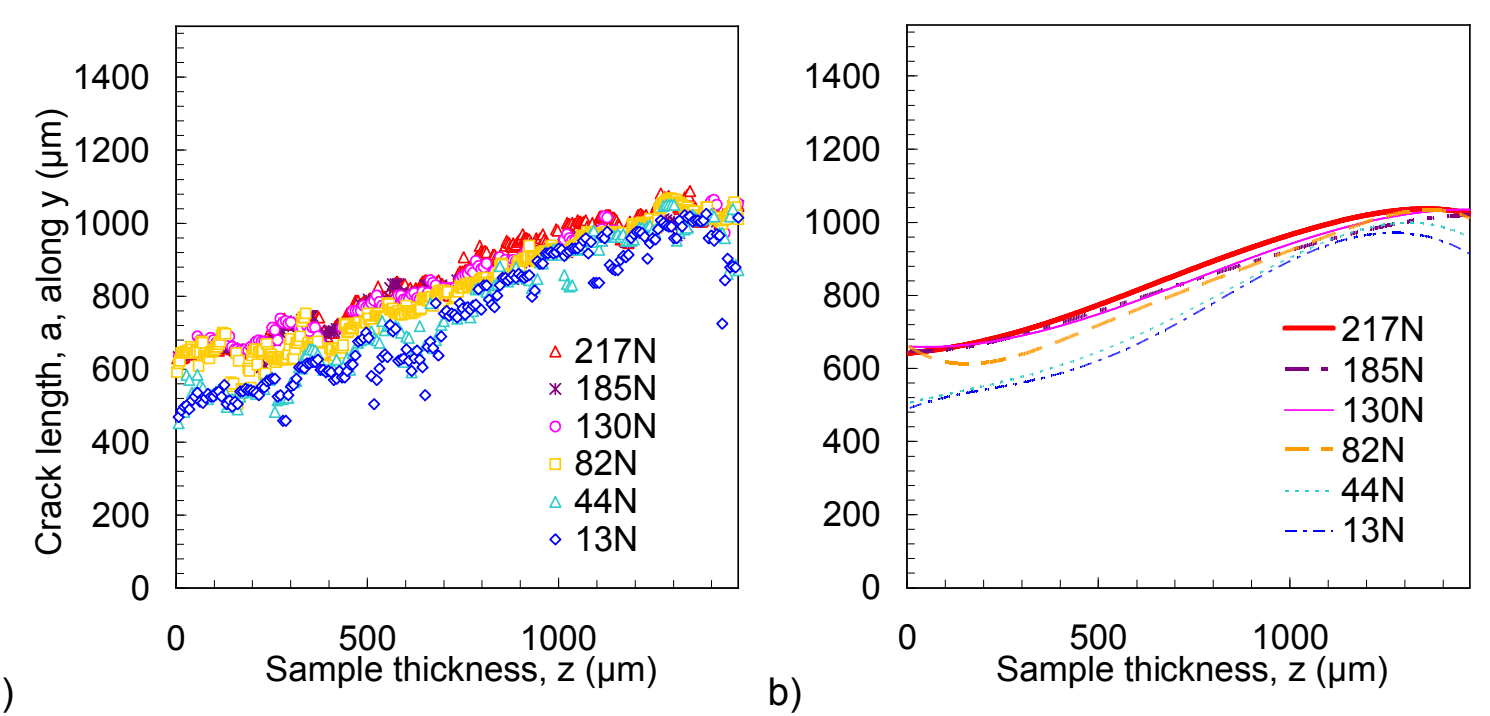

Figure 5 : Position of the crack front for different load levels: (a) experimental points and (b) fitting curves. 


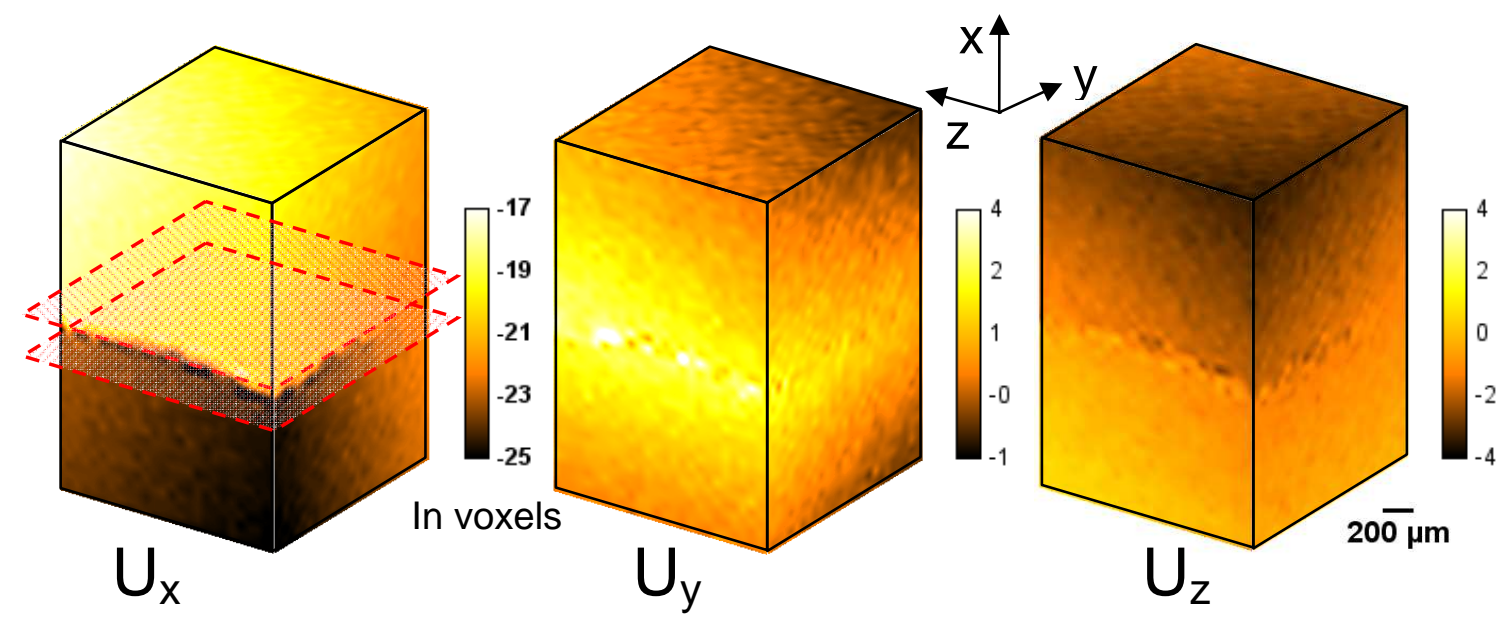

Figure 6 : Displacement (expressed in voxels) fields in the specimen volume under maximum load (macroscopic load applied along $x$ direction). The hatched planes drawn in the $U_{x}$ field indicate the $(y, z)$ planes used for COD mapping in Figure 7. 


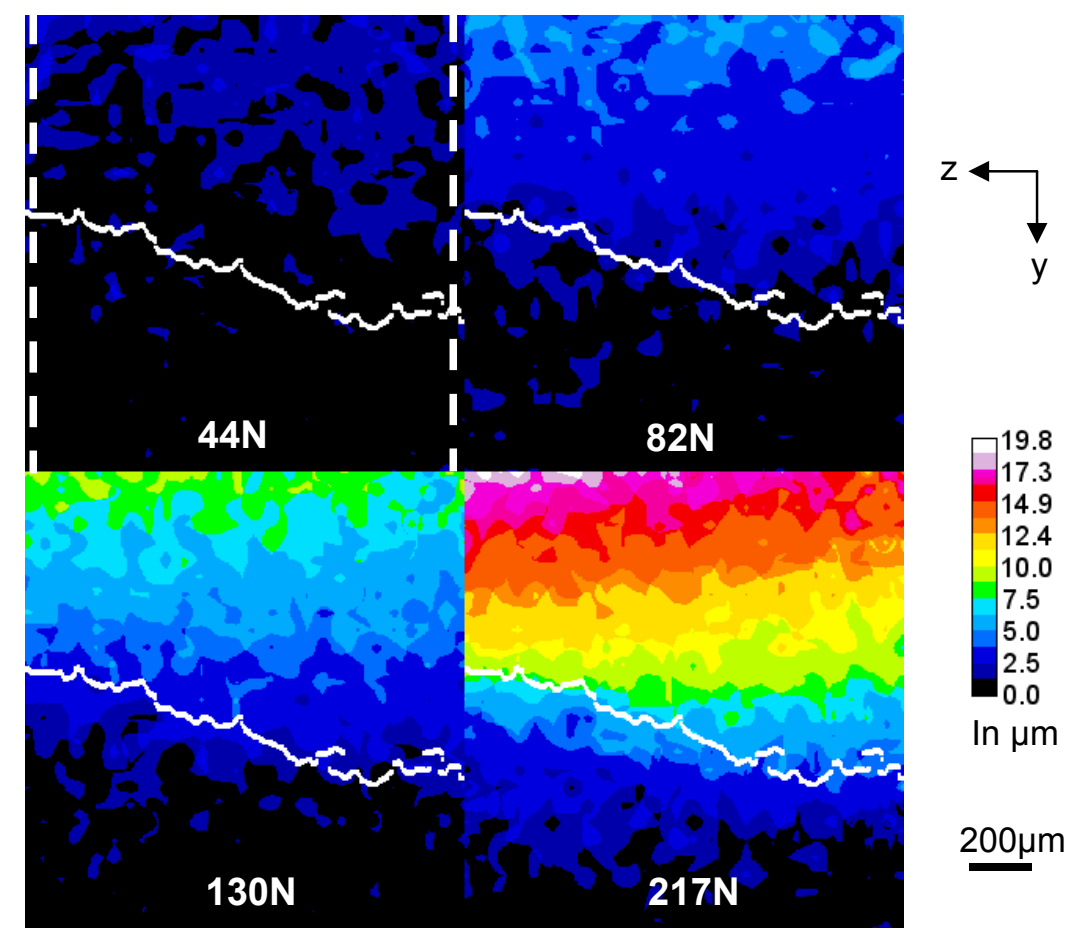

Figure 7 : Maps of $\Delta U_{x}$ displacement (COD) in the specimen cross-section with increasing load. The crack front is drawn in white and the dashed-lines along $y$ direction indicate the location of the profiles plotted in Figure 8. 


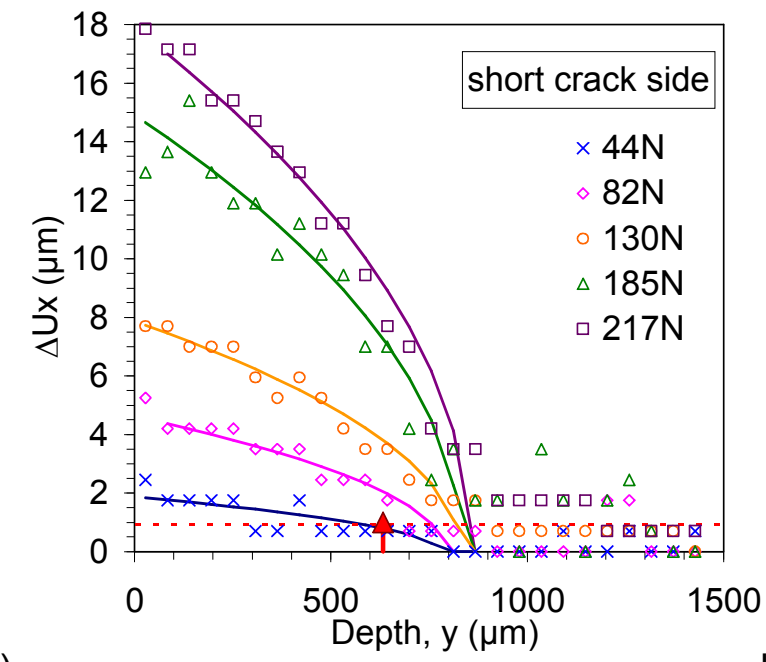

a) Depth, y $(\mu \mathrm{m})$

b)

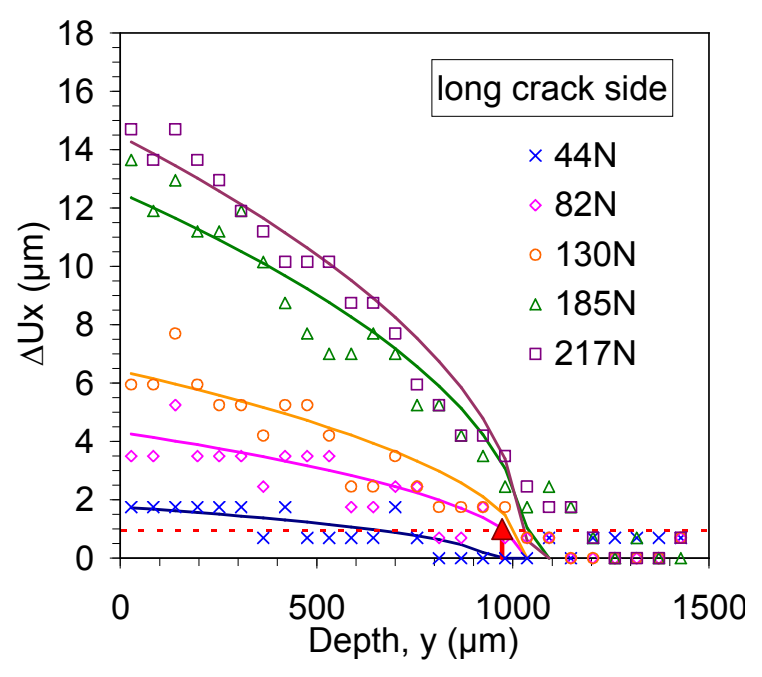

Figure 8 : Change with load of the crack opening displacement profile along crack depth (a) on the short and (b) long crack side; the dashed-line corresponds to 3 times the uncertainty in $U_{x}$ and the arrow indicates the position of the crack front plotted in Figure 7. The solid lines correspond to the best fitting curves. 

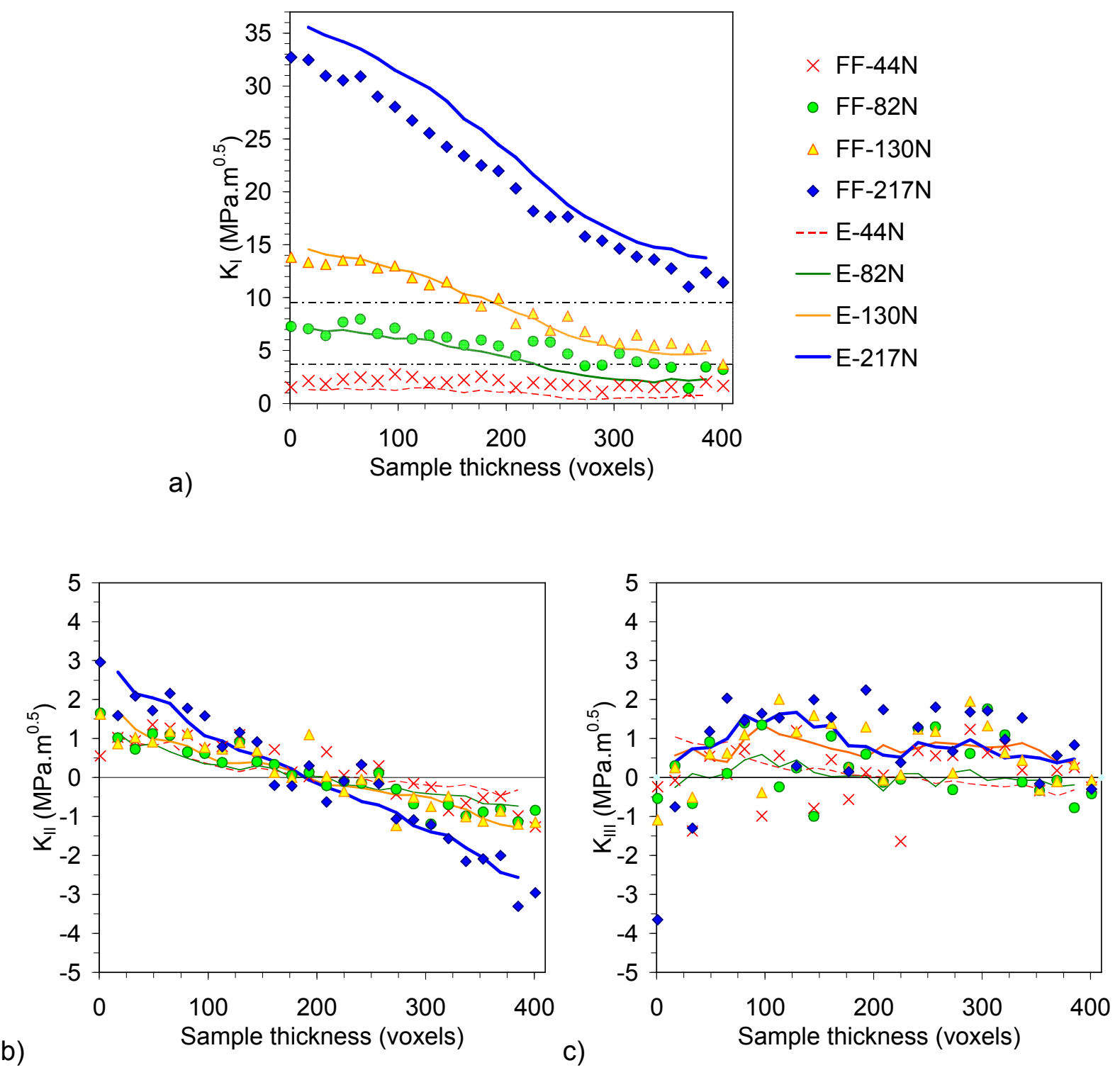

Figure 9 : SIF values along the crack front for (a) Mode I, (b) Mode II and (c) Mode III; Measured ('FF') values of SIF (symbols) are compared to computed ('E') values (lines); the hatched area in (a) corresponds to the $K_{o p}$ range obtained from literature data. 


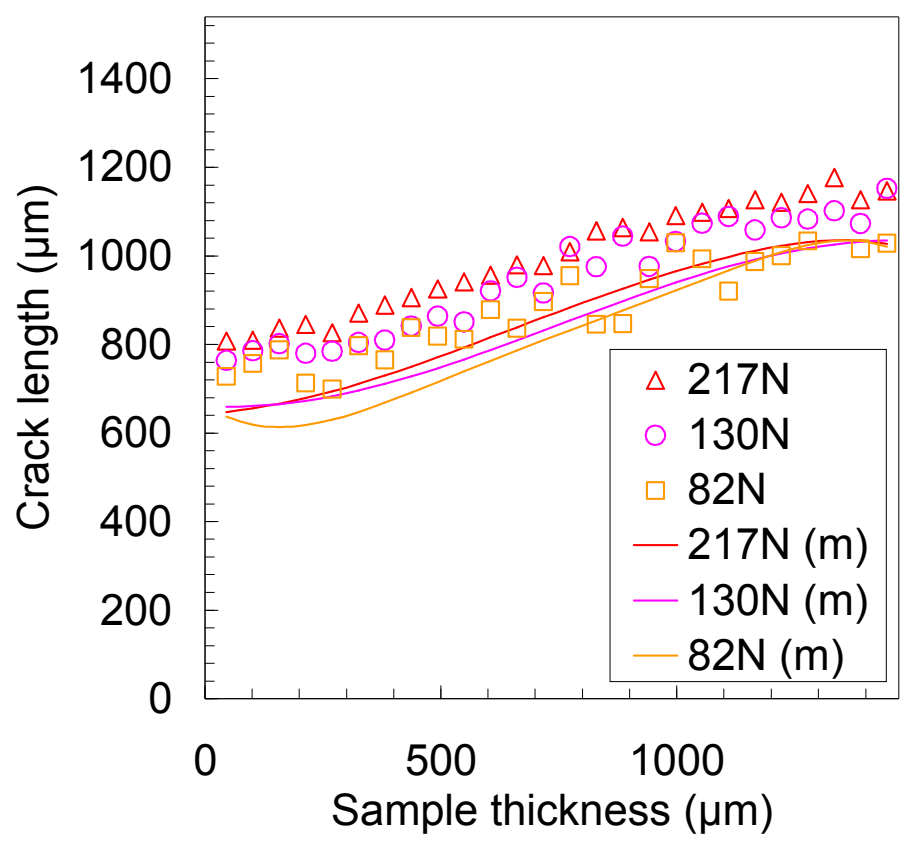

Figure 10 : Crack tip position of the equivalent "elastic crack" based on the SIF extractor method (symbols); the solid lines correspond to the crack tip positions reported in Figure 5b (visual inspection of tomographic images and smoothed by curve fitting). 